\title{
LA INTERVENCIÓN DEL DR. FRANCISCO DIAAZ EN EL PROCESO INQUISITORIAL CONTRA ELENA/O DE CÉSPEDES, UNA CIRUJANA TRANSEXUAL CONDENADA POR LA INQUISICIÓN DE TOLEDO EN 1587
}

\author{
Emilio Maganto Pavón.
}

Servicio de Urología. Hospital Ramón y Cajal. Madrid. España.

\begin{abstract}
Resumen.- OBJETIVO: Dar a conocer, de un modo exhaustivo, un episodio casi inédito en la vida del Doctor Francisco Díaz (1527-1590), cirujano del rey Felipe II, y autor del Primer Tratado de Urología en la historia de la Medicina. Que sepamos hasta la fecha existían pocas noticias de la actuación que, como experto, tuvo que realizar Díaz en el proceso inquisitorial contra Elena/o de Céspedes, un presunto hermafrodita acusado por el Santo Oficio que siendo mujer y haciéndose pasar por hombre, se había casado con otra. El juicio tuvo lugar en Toledo en 1587 y alcanzó gran resonancia en su época, ya que la encausada, vestida con indumentaria masculina y usurpando las prerrogativas del varón, había conseguido fraudulentamente títulos y prebendas vedadas a la mujer, entre ellos la titulación de cirujana. Salvo las referencias de Folch Jou y Burshatin, ambas escuetas e incompletas, ningún autor ni biógrafo del celebre cirujano, había hecho cita de este pasaje de su vida que a nuestro juicio debió suponer para el urólogo un gran quebranto de su reputación.
\end{abstract}

MÉTODOS: Se han revisado los trabajos de los dos autores antes citados, todas las obras y biografías del Dr. Francisco Díaz a nuestro alcance y microfilmado y transcrito en su totalidad el legajo 234, expediente 24, de la Sección Inquisición del Archivo Histórico Nacional de Madrid, correspondiente a Elena de Céspedes (alias Eleno de) (> de 500 folios) para extraer el mayor número de datos acerca de la acusada y sobre la actuación en el proceso del Dr. Francisco Díaz.

RESULTADO Y CONCLUSIONES: La exploración como especialista en órganos génito-urinarios había sido solicitada a Francisco Díaz por el Vicario de Madrid para conceder o no una licencia de matrimonio a dicha mujer que afirmaba ser varón. En su informe de 1586 el urólogo declaró, sorprendentemente, que el peticionario era hombre.

Como se demostraría durante el juicio la encausada, que en su defensa alegaba ser hermafrodita, había logrado engañar al experto con sus 'malas artes' alterando su morfología genital. Gracias a sus conocimientos en cirugía se había automutilado obturando quirúrgicamente su vagina y colocado un 'artificio' para simular que era varón. Al final, tras la opinión de los contraexpertos del Santo Oficio, Francisco Díaz tendría que retractarse, confirmar que era mujer y acusar a la reo de hechicería para salvar su responsabilidad. En el trabajo, sin embargo, concluimos que la acusada era un transexual masculino lo que, en parte, disculparía el error del urólogo 400 años después.

Palabras clave: Francisco Díaz. Inquisición. Transexualismo. Historia de la Urología.

Summary.- OBJECTIVES: To make known, comprehensively, an almost unknown episode in the life of Dr. Francisco Diaz (1527-1590), surgeon of the king Philip II, and author of the first urology treaty in the history of medicine. To our knowledge, to date there were few references about the participation that, as an expert, 
Francisco Diaz had to have in the inquisitorial process against Elena de Cespedes, a presumed hermaphrodite accused by the Inquisition because being a woman married another one pretending to be a man. The trial was carried out in Toledo in 1587 and had great impact in that time, because the accused, dressing with male clothes and usurping the prerogatives of a man, had gotten by fraud titles and favours which were forbidden for women, the title of surgeon among them. Except for the reference by Folch Jou and Burshatin, both short and incomplete, no other author or biographer of the famous surgeon had cited this episode of his life, which to our judgment could mean a great damage to his reputation.

METHODS: We reviewed the works by the two aforementioned authors, all the works and biographies about Dr. Francisco Diaz that we could found, and microfilmed and transcript the whole bundle 234, expedient 24, from the section Inquisition at the National Historical Archive in Madrid, corresponding to Elena de Cespedes (alias Eleno) (> 500 pages) to obtain the greatest amount of data about the accused and the performance of Dr. Francisco Diaz.

RESULTS AND CONCLUSIONS: Francisco Diaz was requested, as an expert, by the Vicar of Madrid to perform the examination of the genitourinary organs to give or not marriage license to that woman saying she was a man. In his report in the year 1586, surprisingly the urologist declared that the petitioner was a man.

As it would be demonstrated during the trial, the accused, who alleged being hermaphrodite in her defense, had been able to deceive the expert with her tricks altering her genital morphology. Thanks to her surgical knowledge she had mutilated herself surgically closing her vagina and placed a device to simulate she was a male. At the end, after the opinion of the counter experts of the Inquisition Francisco Diaz had to retract, confirmed that the accused was a female, and accused her of witchcraft to save his responsibility. Nevertheless, in the work we conclude that the accused was a male transsexual, which, in part, would excuse the urologist's error 400 years later.

Keywords: Francisco Diaz. Inquisition. Transsexuality. History of Urology.

\section{INTRODUCCIÓN}

Hasta la fecha existían pocas noticias de la actuación que, como experto, tuvo que realizar el Dr. Francisco Díaz en el proceso inquisitorial contra Elena/o de Céspedes, un presunto hermafrodita acusado por el Santo Oficio de que siendo mujer y haciéndose pasar por hombre, se había casado con otra. El juicio tuvo lugar en Toledo en 1587 y alcanzó gran resonancia en su época, ya que la encausada, vestida con indumentaria masculina y usurpando las prerrogativas del varón, había conseguido fraudulentamente títulos y prebendas vedadas a la mujer, entre ellos la titulación de cirujana. En su defensa la reo alegaba ser hermafrodita.

Salvo las referencias de Folch Jou (1) y Burshatin (2), ambas muy escuetas e incompletas y que serán comentadas mas adelante, que sepamos ningún otro autor ni los biógrafos (3-7), del célebre cirujano de Felipe II especializado en afecciones de los órganos génito-urinarios y autor del primer Tratado de Urología en la historia de la Medicina, habían hecho cita de este pasaje de su vida que a nuestro juicio debió suponer para el urólogo un gran quebranto de su reputación y que hemos destacado someramente en una comunicación reciente (8).

El motivo de su intervención en el juicio se debió a que fue llamado a declarar por el Tribunal de Toledo para que se ratificase en un informe que sobre la determinación de sexo de la encausada había realizado junto a otro médico, el Dr. Antonio Mantilla, un año antes a petición del Vicario General de Madrid.

\section{Biografía de Elena de Céspedes, alias "Eleno"}

El resumen de la vida y hechos de Elena de Céspedes, alias "Eleno" lasí se le nombra en los documentos), el desarrollo del proceso que la Inquisición de Toledo llevó a cabo contra ella entre 1587 y 1588, y el fallo condenando a la acusada, están escuetamente esbozados en el primer folio del legajo 234 conservado en el Archivo Histórico Nacional (9):

Céspedes - Elena, alias Eleno de - Natural de Alama, esclava y después libre, casó con un hombre y tuvo un hijo; desaparecido y muerto su marido se vistió de hombre y estuvo en la Guerra de los Moriscos de Granada; se examinó de cirujano y se casó con una mujer. Fue presa en Ocaña y llevada a la Inquisición donde se le acusa y condena por desprecio al Matrimonio y tener pacto con el Demonio. Penitenciada a salir al Auto Público de Fe que se celebró en la Plaza de Zocodover de Toledo el domingo 18 de Diciembre de 1588, al que salió en forma de penitente con coroza e insignias que manifestaban su delito; abjuró de leve y se le dieron cien azotes por las calles públicas de Toledo y otros cien por las de Ciempozuelos, reclusión de diez años en un hospital para que sirviese sin sueldo en las enfermerías (Figura 1).

No creemos oportuno en este trabajo ampliar los datos biográficos de la acusada que son dados a conocer extensamente en una obra mía (10) en la que llegamos a la conclusión de que Elena era 
un transexual masculino; tan solo destacaremos que Elena fue juzgada en dos juicios sucesivos, civil e inquisitorial, y que la participación del doctor Francisco Díaz sólo tuvo lugar en el segundo de ellos.

\section{Antecedentes de la obligada participación de Francis- co Díaz en el Juicio Inquisitorial.}

Antes de los juicios, a mediados de 1585, Elena de Céspedes, la acusada que afirmaba ser hermafrodita (según ella primero había sido mujer y luego su cuerpo había sufrido una transformación convirtiéndose en hombre) había comenzado los trámites de su insólito desposorio con una tal María del Caño, natural de Ciempozuelos. Como en todas las bodas sucedidas durante el siglo $\mathrm{XVI}$, para casarse era necesaria la licencia del Vicario y así poder efectuar las amonestaciones en la parroquia del pueblo. Algo raro o anormal debió ver el Vicario de Madrid en el aspecto del varón solicitante, que no tenía vello facial o simplemente su voz atiplada, que le hicieron sospechar que, o no era hombre, o se trataba de un castrado:

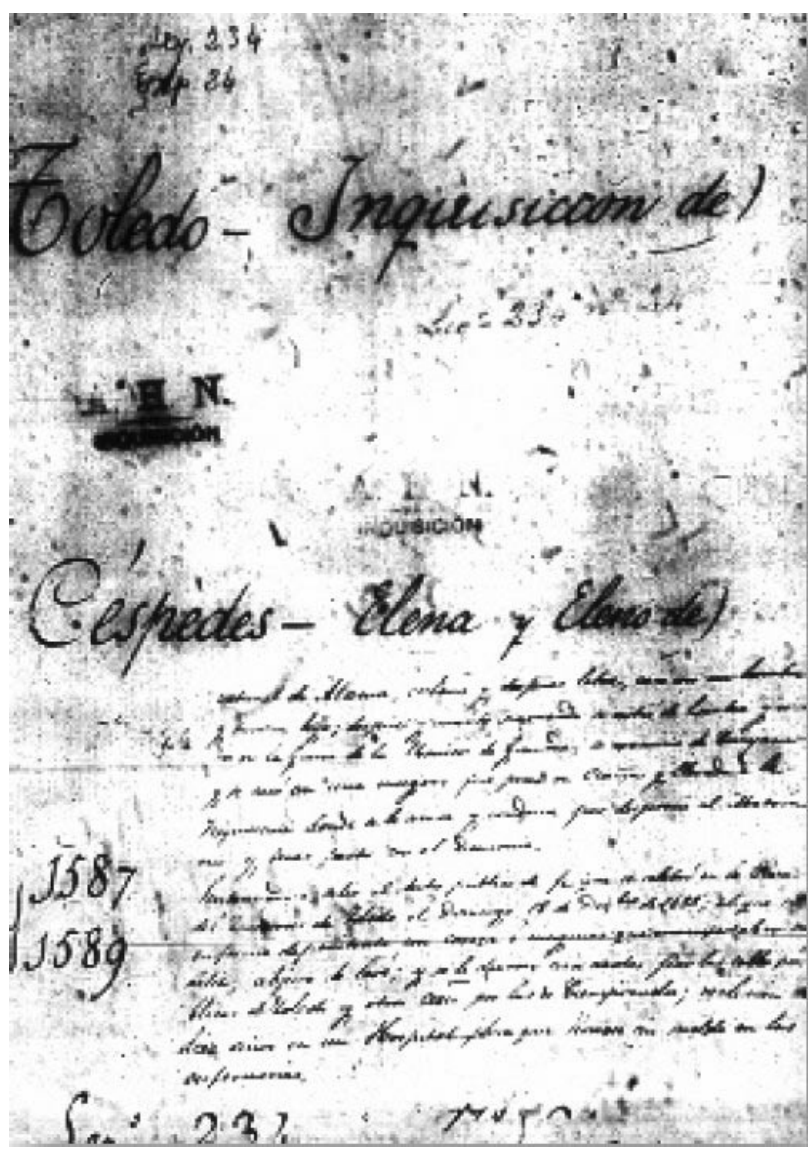

FIGURA 1. Escueta biografía de Elena/o de Céspedes en el primer folio del legajo 234, expediente 24 del Archivo Histórico Nacional de Madrid. "el Vicario viendo a esta sin barbas y lampiña le dixo que si era capón y esta respondió que no, que la mirasen y verían como no lo era"

El Vicario no podía negarse y accedió a la petición de Eleno ordenando que tres o cuatro hombres la examinasen:

"llevaron a esta a una casillla allí cerca y tres hombres o quatro miraron a esta por delante, porque nunca esta consintió que la mirasen por detrás porque no la viesen la cerratura desta de muger, y los dichos hombres dijeron habiendo visto a esta, que era hombre y que no era capón, el dicho Vicario dio licencia a esta para se amonestase y esta llevó la dicha licencia y con ella el dicho cura de cientpozuelos los publicó"

Una vez en su poder la licencia, el párroco de Ciempozuelos publicó las amonestaciones de la boda. Sin embargo, en las publicaciones dos vecinos del pueblo pusieron sendos impedimentos en los que se afirmaba que los contrayentes no podían casarse ya que era "público que Eleno era macho y hembra" y "que tenía dos sexos".

Ante tales trabas, el párroco se negó a casarlos y procedió a devolver nuevamente al Vicario la documentación para que este estudiase el caso. Pero incluso para el Vicario la coyunda comenzaba a resultar complicada:

"Así que esta volvió a Madrid al Vicario por segunda vez y el Vicario mando que la viesen a esta dos médicos de la Corte expertos y que proveería justicia y en cumplimiento del dicho auto quisieron mirar a esta"

Pero antes de ser explorada en Madrid por los médicos expertos de la Corte Elena de Céspedes que, como antes se dijo, había obtenido el título de cirujana en la capital de forma irregular y era muy conocida en esos ambientes por haber trabajado allí durante muchos años, llevó a cabo una serie de maniobras e intentos de retrasar o evitar la exploración de los médicos madrileños. Primero pretendió que la explorasen otros peritos en uno de los pueblos donde trabajaba y donde creyó que obtener una información favorable sería más sencillo. Para lograrlo buscó un grupo de médicos, cirujanos y personas conocidas de ella que la explorasen y dieran razón de que era hombre. Después, con sus conocimientos de cirugía y, según los documentos, ayudada por alguna "comadre morisca", procedió a cerrarse la vagina quirúrgicamente recurriendo además a determinados métodos farmacológicos que produjeran en la vulva y todo el periné quemaduras y queloides que disimularan su condición femenina. Finalmente, aunque este último dato será comentado más tarde, parece 
ser que se colocó un postizo que imitase los genitales masculinos, aunque los documentos no aclaran de que naturaleza era dicho artilugio:

"y yéndose esta a La Guarda y Yepes... esta hizo ciertos lavatorios con vino, balaustras y alcohol y otros muchos remedios y sahumerios, para ver si podía cerrar su propia natura de mujer y aunque no se pudiese arrugar del todo a lo menos que apretase, de manera que pudiese disimularse y con los muchos remedios que esta hizo se le arrugó de suerte que quedó tan estrecha que no la podían meter cosa ninguna. Y así mandó el alcalde que la mirasen los cirujanos y médicos en ese lugar y otras personas, que fueron por todas diez, las quales vieron a esta en una posada de día con una vela o candil y todos tentaron y vieron a esta por delante, y por detrás tentaron solamente, y como esta con los artificios que había hecho estaba tan apretada ninguno de ellos pudo meter el dedo ni conocer questa tuviese seso de mujer, y así que es verdad que tentaban una dureza del arrugamiento que había hecho. Preguntaron a esta que era aquello y que esta les respondió que de una almorrana que había tenido alli o apostema, le habían dado hacer un botón de fuego y le había quedado aquella dureza. Y con este engaño todos los diez dichos hombres, así médicos como los demás que la miraron declararon y dijeron sus ojos ante el alcalde afirmando no tener esta seso de mujer y diciendo que tenía miembro de hombre, y el dicho alcalde dio a esta la información en forma y con ella esta se fue a Madrid y la presentó ante el Vicario" (Figura 2).

A pesar del informe favorable de los médicos y cirujanos de Yepes, el Vicario de Madrid no parece que quedó conforme y se refrendó en su anterior provisión de que a Eleno le examinaran dos médicos peritos de la Corte. La cirujana, como la primera vez, debió sentirse preocupada por tener que ser vista en Madrid por los médicos reales expertos y volvió a autolesionarse aún mas los genitales, pero esta vez con métodos más fuertes y violentos que debieron ocluir definitivamente su vagina:

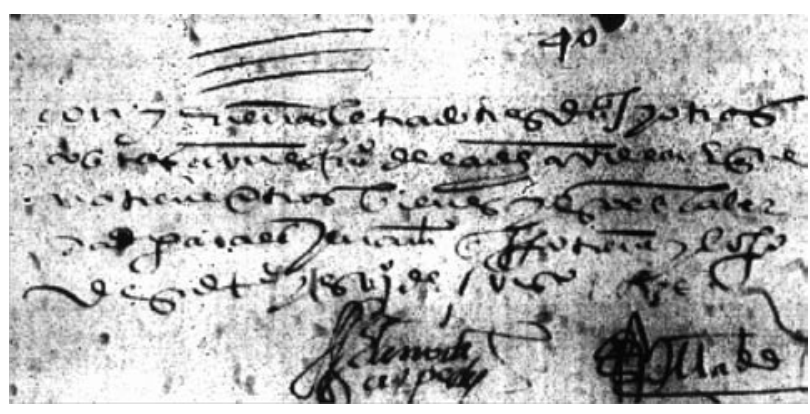

FIGURA 2. Firma y rúbrica de Eleno de Céspedes (Elena) en una de sus declaraciones. "el Vicario proveyó por ende que la reviesen conforme a lo proveido por el y esta volvió a hacer todos los remedios que esta se había hecho ya, apretarse y otros más fuertes que supo"

\section{Detalles de la exploración del Dr. Francisco Díaz acer- ca de la determinación de sexo de la acusada.}

El 17-2-1586, los doctores Francisco Díaz, médico y Cirujano de Cámara del rey Felipe II especializado en afecciones génito-urinarias, y el doctor Antonio Mantilla, médico de Madrid, a petición del Vicario de la capital realizaron una exploración a Eleno de Céspedes. Según consta en el sumario, la inspección fue realizada en una casa de la calle de Toledo:

"ante el Señor Vicario general pareció el doctor Francisco Díaz, médico y cirujano de Su Majestad, del cual fue recibido juramento en forma... dijo que el vido al dicho Eleno de Céspedes y que es verdad que ha visto sus miembros genitales y los márgenes vecinos y a la vista de estos y tocado con las manos, y que declaraba como declaró que el tiene su miembro genital el qual es bastante y perfecto con sus testículos formados como cualquier hombre y que en la parte inferior junto al ano tiene una manera de arrugación que a su parecer a lo que tocó y vido no tiene semejanza de cosa que pueda presumirse ser natura, porque procurándole tocar no pudo ni fue posible hallarle perforación alguna de que se pudiese presumir tal cosa y así declaró que a su parecer no tiene semejanza de hermafrodito ni cossa dello. Y que esta es la verdad para el juramento que hizo. Y lo firmó de su nombre" (Figuras 3 y 4).

La exploración e informe del doctor Mantilla fue en todo similar a la del doctor Francisco Díaz por lo que obviamos transcribirla. Ante estas informaciones el Vicario no tuvo más remedio que otorgar la licencia de casamiento:

"entonces con esta información, reconociendo ante el Vicario ser esta la misma que los médicos habían visto y examinado, dio licencia a esta para que se casase"

\section{El juicio civil de Ocaña. Eleno/a de Céspedes acusada de varios delitos. El doctor Francisco Díaz denunciado por incomparecencia ante las juntas de Madrid.}

Después de conseguir la licencia Eleno de Cèspedes se desposó con María del Caño en Yepes y durante mas de un año hicieron vida en común sin que trascendiera ningún escándalo, ni su vida sexual fuera motivo de sospecha o puesta en entredicho. La cirujana continuó trabajando en el pueblo y en varios lugares comarcanos. Pero como era de prever, tanta 
paz no podía durar mucho. Eleno era demasiado conocida en los pueblos por los que deambulaba, pero también lo era su ambigüedad. Un antigüo conocido la denunció al Gobernador y Justicia Mayor:

"dijo que denunciaba e denunció a Eleno de Céspedes, estante en esta villa, porque el susodicho siendo mujer anda en hábito de hombre por esta villa contra las premáticas y leyes destos Reinos y so color de andar en hábito de hombre está casado con María del Caño su mujer sin ser hombre"

Tras la denuncia, el alguacil detuvo a la demandada encarcelándola en Ocaña, entablándose un juicio civil contra ella que tuvo una duración de cerca de un mes (desde mediados de junio hasta el 4 -VII de 1587). Eleno fue acusada de diversos delitos y durante la causa nuevamente varios médicos, cirujanos y matronas, a requerimiento del tribunal, volvieron a explorar a la acusada. Esta vez quedarán al descubierto algunos detalles de su feminidad no constatados en anteriores exámenes:

"el doctor Villalta médico y el licenciado Vascones cirujano, e habiéndole visto e mirado, no tenía

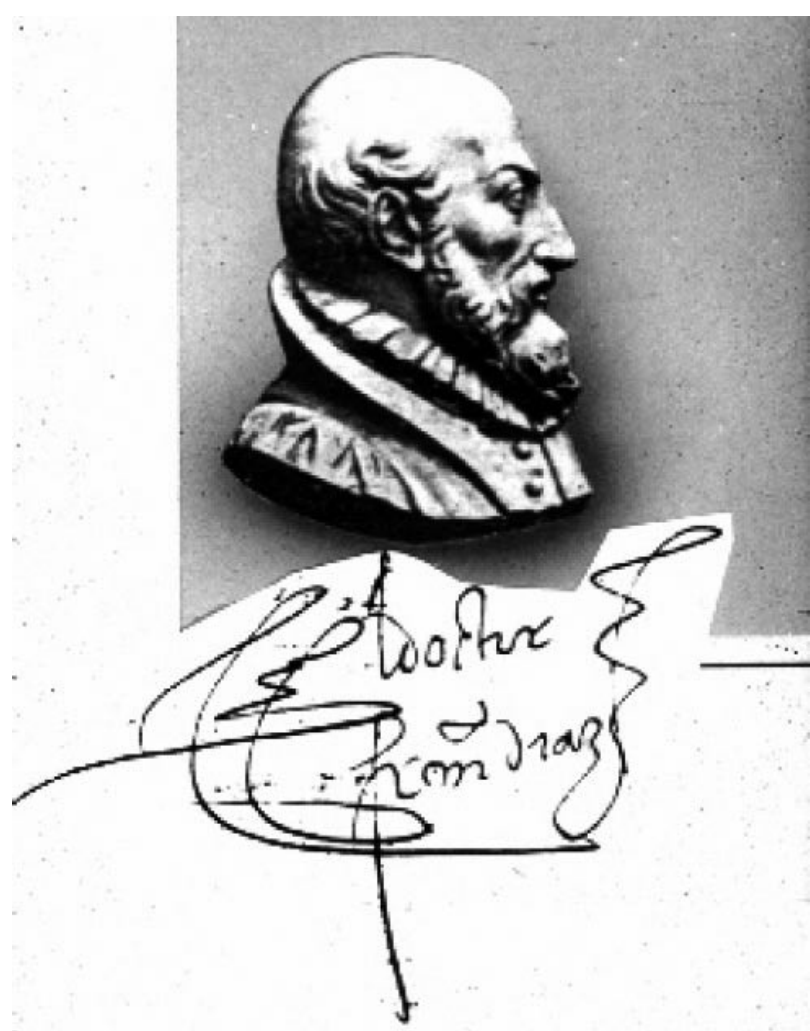

FIGURA 3. Representación figurada de la efigie del Dr. Francisco Díaz tomada del relieve del claustro del antiguo Colegio de San Carlos (Colegio Oficial de Médicos de Madrid). Firma y rúbrica auténticas del mismo en un documento oficial de Madrid. ni tiene señal ny miembro de varón, ni lo había tenido, sino solamente sexo de mujer y en su angostura... muestra ser esta mujer"

"juntamente el doctor Gutiérrez médico y el licenciado Vazquez curujano, han visto a la dicha y declararon que realmente no es, ni ha sido hombre sino mujer, a la qual vieron y constataron su vaso natural semejante al de otras mujeres, con todas las señales de mujer como son altura de cuerpo, pecho y rrostro y habla, y de todo lo demás, de que se infiere ser mujer"

Tras este último contra-examen parece inconcebible, al igual que debió parecerle al tribunal, que los primeros expertos médicos, fundamentalmente el doctor Francisco Díaz de gran prestigio profesional en la Corte por ser médico de Cámara del Rey y como sabemos especializado en enfermedades de los órganos génito-urinarios, emitiera su informe sin realizar una exploración corporal completa de la acusada. El célebre cirujano de Felipe II debió quedar muy "tocado" a raíz de su dudoso dictamen, aunque en su disculpa podemos admitir que la acusada, recluida en la cárcel de Ocaña, esta vez no pudo someterse a las auto-mutilaciones o a colocarse algún

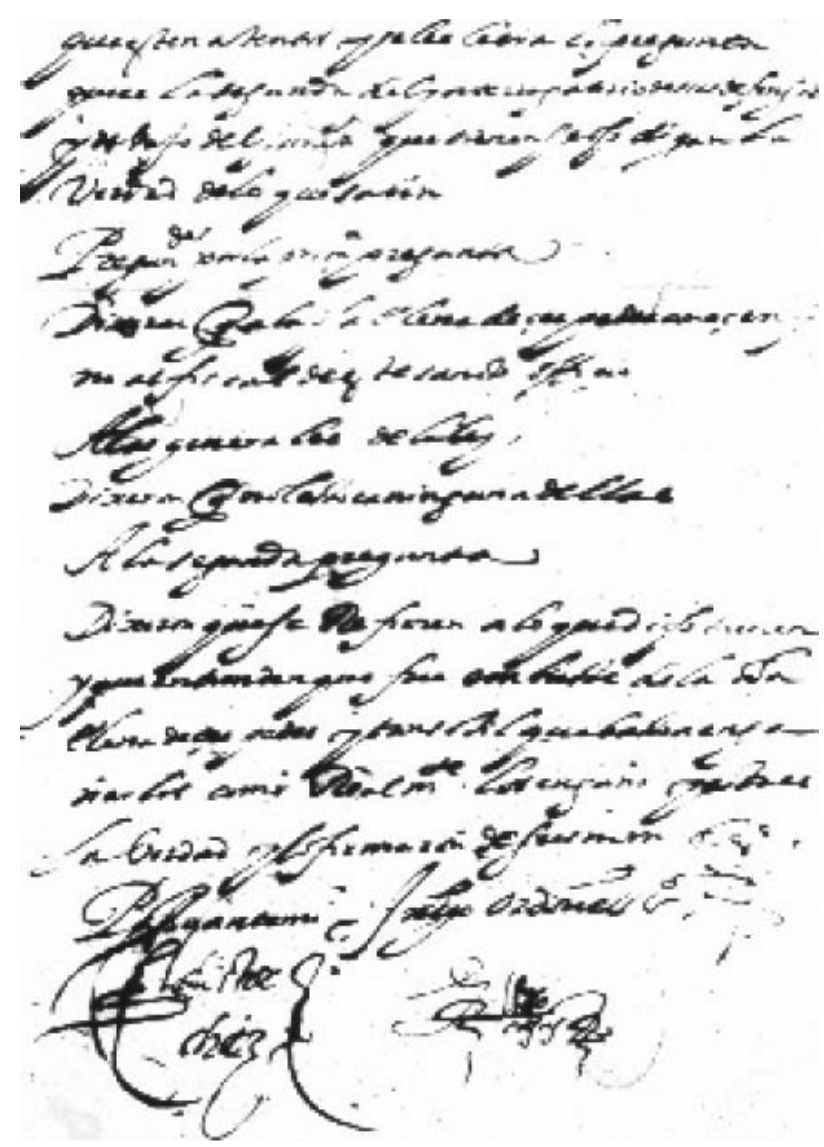

FIGURA 4. Firma y rúbrica del Dr. Francisco Díaz en una de sus declaraciones durante el juicio inquisitorial. Como puede comprobarse es idéntica a la anterior. 
postizo, estratagemas que seguramente le sirvieron para engañar al médico de Cámara.

Pero lo que fue definitivo para determinar si Eleno era mujer y echar por tierra los controvertidos informes de los médicos de Yepes y de la Corte, fue la exploración de las matronas, las cuales, aparte de consignar detalles muy importantes sobre sus pechos y complexión, consiguieron incluso introducir parcialmente una candelilla por la vagina de Eleno, que como recordamos había sido obturada artificialmente por ésta, y cuya maniobra el doctor Francisco Díaz no había podido realizar:

"promoviose juramento a Inés López de la Peña comadre y vecina de la villa, la qual después de haber jurado... testificó... que la dicha Elena de Céspedes acusada en este proceso, la cual testigo ha visto y mirado juntamente con Mari Gómez e Isabel Martínez, que la dicha es mujer e tiene natura de mujer y se le metió por ella una vela dentro e por cantidad por dicha natura... la cual entró premiosa y poco, y con esto esta testigo no entiende que háyanle echado varón a ella. También le vio las tetas y es tan gorda que tiene los pechos grandes conforme al cuerpo, y pezones, los cuales tiene sino de mujer, y tiene el pecho desbaratado en alguna manera"

Quedaban claras las modificaciones que la acusada había efectuado en su anatomía, incluido el "desbaratamiento" de sus pechos, para simular que era varón. También parecía evidente, según siempre Eleno defendió, que la reo no había vuelto a mantener relaciones sexuales con ningún otro hombre después del parto de su único hijo.

Ante tales informes que hacían dudar de la honorabilidad y pericia de los médicos de la Corte, el tribunal se vio obligado a llamar a declarar a los doctores Francisco Díaz y Mantilla para que se retractasen o volviesen a examinar a la acusada. El doctor Antonio Mantilla acudió a Ocaña el 1-VII-1587 para testificar y después de un interrogatorio severísimo durante el cual el tribunal casi le llegó a acusar de encubridor, el médico no tuvo mas remedio que admitir que el examen se había hecho en malas condiciones e incompletamente. La exploración efectuada por él y el doctor Francisco Díaz aunque se había realizado de día, en el aposento apenas había luz y a Eleno solo se le miraron sus genitales por delante para ver si era varón, única cosa que le interesaba al Vicario. No obstante, Mantilla se debió ver presionado por el tribunal y temiendo ser acusado de falsedad, perjurio o encubrimiento, acabó cediendo a las presiones sugiriendo que la acusada les había engañado mediante artes de hechicería, lo cual abría un nuevo e inusitado campo a las acusaciones del tribunal: "dijo que vio en Madrid, como declaró entonces, ser hombre la dicha Elena y que le había tentado las partes de hombre y tenía sexo de barón // Dixo que no puede entender la causa mas de que entiende que sea alguna ilusión del diablo y que la dicha Elena de Céspedes debe ser hechicera... lo qual declaró bajo juramento"

Consta que el doctor Francisco Díaz, el otro experto motivo de este trabajo, y los médicos de Yepes a pesar de ser citados también a declarar en Ocaña no acudieron a la citación por lo que fueron denunciados por incomparecencia por Andrés de Liñán ante las juntas de Madrid.

"Otrosi, pido a Vmd mande dar su carta e juntamente requisitoria para las juntas de la villa de $\mathrm{Ma}^{-}$ drid y de la de Yepes y otras partes, para que parezcan personalmente ante Vmd el doctor Francisco Díaz médico del Rey NNo Sr. y los médicos de la villa de Yepes, los cuales tienen declarado ser hombre la dicha Elena de Céspedes para que la vean y reconozcan y declaren como esta es mujer y ansí se entienda que hechizos y encantaciones y lo demás que la tengo acusada"

Un tema que al tribunal civil le preocupó mucho desde el principio del juicio fue la existencia o no del presunto "miembro de varón", base principal de la argumentación de Eleno para justificar sus actos alegando que era hermafrodita. Si la acusada demostraba que lo tenía o lo había tenido, su declaración de que era varón y hembra podría eximirle en parte de las acusaciones de usurpación de género y matrimonio ilícito. Si se demostraba que la existencia de tal miembro viril era una patraña inventada por la acusada, el delito podía ser gravísimo pues podía ser acusada de sodomía. Por eso las preguntas que se le fueron haciendo a Eleno desde el principio de la causa fueron variando conforme los contra-exámenes médicos iban demostrando su naturaleza femenina y la inexistencia de tal miembro.

Para defenderse, la encausada se vio obligada a variar ligeramente su primera declaración afirmando que el pene con el que mantenía relaciones con su esposa y anteriormente con otras mujeres como cualquier hombre, había sido asiento de una enfermedad "cancerosa" durante su estancia en Villarrubia, uno de los pueblos que visitaba, y "se le había caído" totalmente, junto a los testículos durante su permanencia en la prisión.

Según su relación, durante su enfermedad "se había curado ella misma cortándolo poco a poco hasta que se le cayó definitivamente". El alegato de Eleno debió parecer irrisorio y totalmente inverosímil al tribunal, pero como siempre la ciru- 
jana trató de demostrar sus afirmaciones con datos científicos:

"preguntada como de presente tiene sexo de mujer y como ni tiene señal de haber tenido seso de hombre, como lo tienen declarado los médicos e cirujanos que la vieron / / Dixo que ella tubo seso de hombre e compañones e se le cayó. Cansado de andar a caballo se le vino a llagar // Preguntada en que lugar estaba cuando le dio el cáncer, que cirujanos le curaron y que tiempo / / Dixo que le dio en Villarrubia el dicho cáncer, recien venida desde Aranjuez y que ella propria se curaba... y que le duró la dicha enfermedad diez y ocho días y que iba cortándolo [el pene] poco a poco y que todavía tenía las llagas por cerrar"

Sin embargo Eleno no logra convencer a nadie con su montaje y menos al tribunal. Para el fiscal comenzaba a estar claro lo que la cirujana pretendía y sus preguntas van a ir ya decididamente a probar el delito de sodomía de la acusada y demostrar que en el coito con María del Caño, su esposa, hubo penetración, comportamiento exclusivamente masculino, y que a falta de miembro viril la acusada había hecho utilización de un instrumento que lo sustituía o simulaba. Según la ley, la pena capital en estos casos era mucho más merecida:

"preguntada si es verdad que prosiguiendo en el dicho delito y añadiendo fingiendo tener natura de hombre y con miembro postizo y artificial imitando al natural de hombre y fingiendo serlo tubo acceso y cópula a la dicha María del Caño y la corrompió con el dicho miembro postizo artificial"

"preguntada con que miembro y de que metal - materia era con lo que conocía a la dicha María del Caño y le hacía entender ser el natural de hombre"

Entraba en escena la "inocente y cándida" esposa. Sus declaraciones y el examen de sus genitales por los expertos y matronas, eran fundamentales para el proceso. Si el tribunal llegaba a demostrar que ésta había perdido su virginidad, el delito de sodomía quedaría demostrado y no harían falta mas pruebas ni acusaciones. Pero a su vez la cónyuge podía ser también acusada de complicidad, lo que la hacía vulnerable a la pena capital.

Las respuestas de María del Caño confirmarían estos hechos y también las declaraciones ulteriores de Eleno, aunque ninguna de ellas debió convencer al tribunal:

"que diga e declare... de que modo y manera se han conocido y tenido cópula y junta carnal con apercebimiento"
"Dixo que jura que Eleno es hombre y que la avía corrompido y tenido sospecha de preñado del"

"Dixo que la a conocido como tal hombre usando con ella como hombre con mujer... la cópula y junta carnal han tenido muchas veces echándose sobre esta confesante y otras veces de lado en la cama y aunque le metía por su natura esta confesante nunca vio lo que era, mas que parecía cosa lisa y tiesa"

Parecía evidente que María había perdido su virginidad con Eleno, pero la cirujana trató de convencer a los jueces explicándoles que había desflorado a su esposa antes de que se le cayera el pene, cuando era hombre y antes de casarse con ella, ya que era hermafrodita:

"quando se casó en Cientpozuelos con la dicha mujer [María] nunca ella supo ni sospecho que se casara con otra mujer, porque antes de casarse con ella, la dicha Elena de Céspedes la avía habido su virginidad y tenido accesso a ella muchas veces y ansi la dicha mujer no podía entender que se casara sino con hombre, pues la dicha Elena hacía obras de tal... y que cuando se casó aunque era mujer también era hombre por tener sexo de tal y ser potente para casarse"

Aunque no lo pretendiera, con esta última declaración Eleno se autoinculpaba del delito de sodomía y al tribunal solo le restaba demostrar que María del Caño había perdido su virginidad con ella.

El 27 de junio de 1587 varias matronas exploraron a María en la cárcel de Ocaña por orden del gobernador a fin de comprobar "si ha conocido y ha sido usada de varón". Por esas fechas María ya había sido detenida y encarcelada acusada de complicidad. En declaraciones separadas las matronas afirmaron lo siguiente:

"Inés López: "la dicha María del Caño está corrompida" "Mari Gómez: "está corrompida, ancha y amplia"

"Isabel Martínez: "está corrompida según naturaleza"

La acusación final del delito de sodomía para ambas mujeres parecía evidente y así debió verlo el tribunal el 4-VII-1587 promoviendo, por intermedio de Andrés de Liñán, alguacil de Ocaña, una querella contra ellas. Dada la importancia de las imputaciones para el futuro de la causa he querido transcribirla íntegra a pesar de su extensión:

"Lorencio Gómez en nombre de Andrés de Liñán, alguacil de esta provincia, ante Vmd. me querello de Elena de Céspedes, natural de Alama, presa en la cárcel de esta gobernación, e de María del Caño, vecina 
de Cientpozuelos, a las quales acuso criminalmente y contando el caso de esta mi acusación presupuesta qualquier solemnidad que el delito en semejante caso requieren, digo que las dichas por mi acusadas con poco temor de Dios № Sr, e menosprecio de la Real Facultad, siendo como la dicha Elena de Céspedes es mujer sin tener seso de barón ny rastro de serlo, se vino de muchos años aquí y ilícitamente anda en ávitos de hombre ovrando como curviano, y no contenta con esto de catorce meses a esta parte, poco más o menos, siendo esta mujer se casó y veló yn facie eclesie con la dicha María del Caño y para ello con hechizos e incantaciones engañó a los médicos que la vieron en Madrid para que declarasen que era hombre como declararon y aciendo burla del Santo Sacramento del Matrimonio e siendo tal mujer se casó con la dicha María del Caño con la qual a estado casada catorce meses y más tiempo, con la qual a tratado carnalmente e tenido quenta con un instrumento tieso y liso con el qual cometió delito de nefando desta manera con la dicha María del Caño. Ansí mismo sabiendo que esta era mujer y que le bajaba su regla como a las demás mujeres, como ella confiesa, consintió e tuvo por bien que tuviese trato con ella muchas veces con el dicho instrumento tieso y liso con el qual la corrompió, como de presente está corrompida, cometiendo juntamente con ella el dicho pecado de sodomía, viviendo más casada con la dicha Elena de Céspedes haciendo burla del Sacramento del Matrimonio de lo qual están convencidas por el proceso que, claramente de las contradicciones, de sus confesiones, e de todas demás culpas que contra ellas resulta, las acuso que cometieron muy graves y atroces delitos dignos de ser por Vmd. castigados. Por ende de las dichas Elena de Céspedes y María del Caño en cumplimiento del juicio e que avida esta my relación por ser berdadera en la sentencia la que el caso e lugar aya declare a los husos legales y a cada una de las, por seguras y perpetradoras de los delitos, que se las tenga apresadas y declaradas, las condene a las mayores y más graves penas que por ello incurrieron según las leyes y premáticas de estos reinos ejecutándoseles sue personas presentes para que sean castigadas con ejemplo porque otros tomen de no cometer semejantes delitos y sobre todo pido cumplimiento de jueces por la vía e remedios que más aya lugar con las costas, e juzguen en forma, que no acuso de malicia.

Quedaban claros para el tribunal los delitos de Eleno como lo eran la usurpación de hábito masculino y de las prerrogativas del varón -incluido el título de cirujano-, el de burlarse del sacramento del matrimonio, el de posible hechicería, pero sobre todo el delito de sodomía (crimen nefando) con otra mujer, a la cual había desflorado con un instrumento que simulaba el miembro viril. María del Caño, su "esposa", también fue acusada de sodomía por haber consentido y encubierto los hechos. De todas las acusaciones la más grave era la del crimen nefando que, como antes vimos, acarreaba la pena de muerte en la hoguera para las dos mujeres.

Sin embargo la justicia laica no podrá terminar el proceso. Denunciado el caso por un capellán de Ocaña a uno de los comisarios de la Inquisición, el Santo Oficio de Toledo va a exigir que se le transfiera el dossier y las dos prisioneras. La instrucción estaba terminada y el auto de acusación para ambas concluido, sin embargo las autoridades civiles tendrán que inclinarse ante la petición del Santo Tribunal.

\section{El juicio inquisitorial de Toledo contra Elena de Céspe- des. El Doctor Francisco Díaz obligado a comparecer ante el Santo Tribunal y a retractarse de su primera declaración acerca de la determinación de sexo de la acusada.}

A diferencia del Tribunal civil, la Inquisición consideró que existían delitos mucho más graves que la sodomía en el dossier de Eleno de Céspedes. El Santo Tribunal va a orientar la causa de diferente manera anteponiendo las acusaciones de apostasía y hechicería, cargos mucho más severos que podían ser juzgados con mayor rigor y que por su gravedad la mayoría de las veces también acarreaban la hoguera para los acusados.

Sin embargo, el Santo Oficio era mucho más estricto y concienzudo en sus pesquisas. Aunque en el juicio el tribunal no tendrá mas remedio, nuevamente, que orientar la causa hacia el supuesto hermafroditismo de la cirujana para tratar de desmontar la argumentación de su doble condición, las preguntas del fiscal tendrán un claro derrotero: probar que el presunto hermafroditismo de la acusada es una patraña y que Eleno, siendo mujer, ha violado conscientemente la moral y las normas del sacramento del matrimonio casándose con otra por lo que había incurrido en un delito de herejía (Figura 5).

El tribunal civil de Ocaña ya había probado mediante los contra-informes médicos y los de las matronas que Eleno no era hermafrodita y que todas las argumentaciones de la reo eran un embuste. Sin embargo el Santo Oficio era más minucioso en sus investigaciones y mucho más duro cuando se trataba de juzgar los delitos, máxime si estos eran de su competencia o si en la comisión de los mismos podían estar involucradas terceras personas.

La audiencia de Ocaña había logrado acreditar que Eleno era mujer, que no tenía miembro de varón, que había incurrido en un delito de sodomía y que los informes médicos de Yepes, pero fundamen- 
talmente los dictámenes de los doctores Mantilla y Francisco Díaz, eran falsos.

El Dr. Mantilla en un nuevo examen de la acusada practicado en Ocaña se había retractado de su primer diagnóstico habiendo afirmado bajo juramento que la cirujana era mujer y que posiblemente le había engañado mediante intervención y ayuda del demonio.

Eran pues, los controvertidos primeros informes de los médicos de Madrid y Yepes el meollo de la cuestión y lo que había dado lugar a todo el embrollo posterior. La Inquisición lo debió interpretar así porque desde finales de julio hasta el mes de octubre de 1587 los interrogatorios se centrarán en el tema del hermafroditismo con la comparecencia de un sin fin de testigos que declararán a favor y en contra de Eleno. En mi opinión la causa adquirirá desde ese momento un interés que hoy podríamos definir como científico, ya que en ningún proceso de la Inquisición

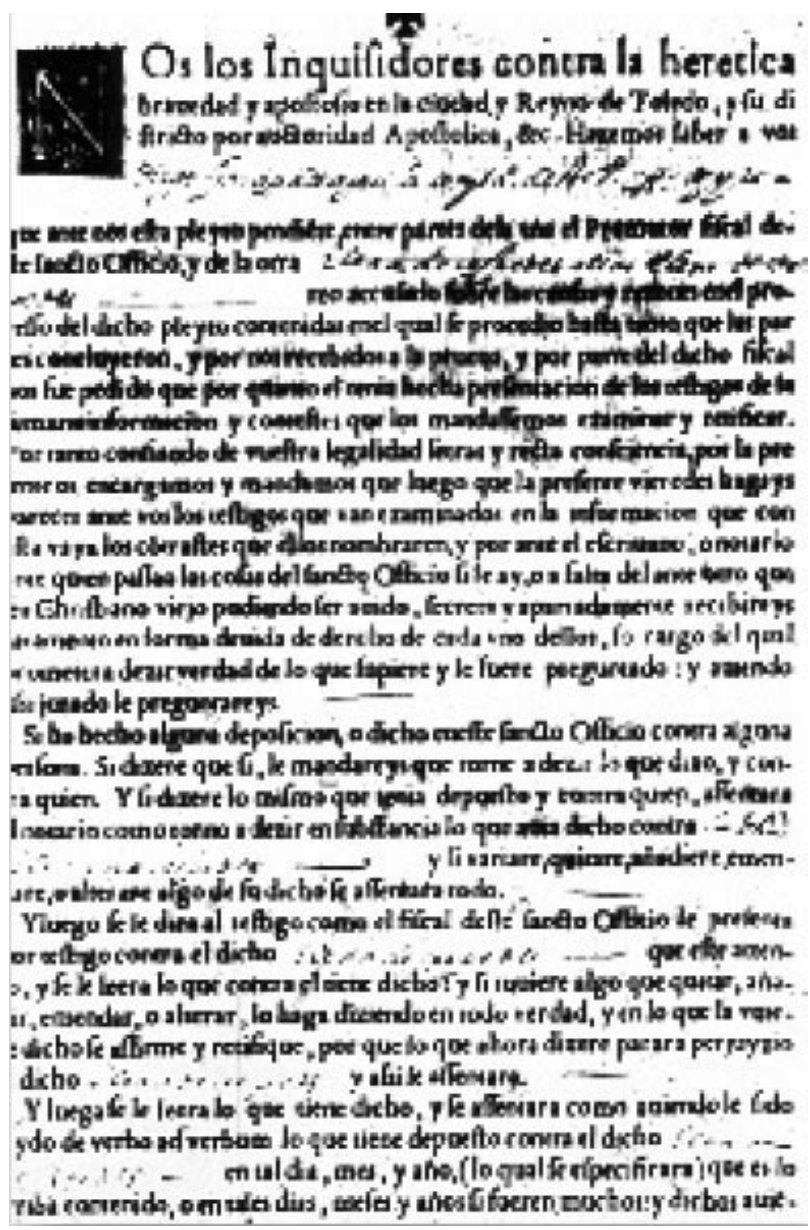

FIGURA 5. Documento impreso de acusación de herejía y apostasía de la Inquisición toledana contra Elena/o de Céspedes. Era un impreso habitual en todos los procesos. entre los siglos XV a XIX he encontrado detalles tan interesantes, desde el punto de vista urológico, como los que aparecen reseñados en este juicio.

El fiscal procurará, no solo volver a demostrar que Eleno es mujer, que no es hermafrodita y que no tiene ni ha tenido nunca miembro de varón, sino que también intentará involucrar a los expertos médicos que testificaron en su favor acusándolos de impedientes, complicidad, soborno y encubrimiento.

La acusación de resabio de herejía quedaba implícita de nuevo si el fiscal llegaba a demostrar que la reo no era hermafrodita:

"fuele dicho a esta que si es verdad lo que tiene dicho acerca del miembro de hombre que es ficción y embuste, porque esta nunca fue hombre sino mujer como nació... y para que este tribunal se huse con ella de misericordia, es decir enteramente la verdad, que diga el embuste que hizo y la forma que tubo para engañar a los testigos que dijeron en favor de esta y si les dio o prometió algo, y que es lo que la movió, siendo mujer como es, casarse con otra, y si la dicha María del Caño sabía que esta era mujer cuando se casó con ella"

Eleno perseverará en sus declaraciones durante el juicio de Ocaña afirmando que no sobornó a los testigos, que cuando se casó era hombre, que su vida itinerante solo le permitía tener relaciones pasajeras e ilícitas y que fue el respeto por la religión y la moral lo que le movió a buscarse una esposa para fundar un matrimonio estable con María del Caño. Con su, para ella, correcto comportamiento, no solo negaba ser hereje sino que se había casado conforme a las normas de la Iglesia:

"Dijo que no dio ni prometió cosa ninguna a ningún testigo para que dijeran que lo era, aun algunos testigos presentes ante el Vicario de Madrid, quando se quiso casar con la dicha María del Caño, juraron que conocían a esta mas de doce años y le tenían por soltero pensando ser esta hombre"

"Dijo que esta se vio con miembro de hombre y que podía tener acceso carnal a mujer como hombre, y como andaba con muchas quiso salir del pecado, casarse y no tener que hacer más que con su mujer, y por esto se casó, que no pensó que en ello heraba, antes pensó que estaba en servicio de Dios" (Figura 6)

Pero el fiscal de la Inquisición no estaba dispuesto a continuar contemporizando. La opinión de los expertos médicos era totalmente necesaria para, de una vez por todas, acabar con la patraña del hermafroditismo. 
La tarde del 13-VIII-1587 fueron convocados a la audiencia para declarar los doctores De la Fuente, Villalobos y el licenciado Juan Gómez cirujano, todos ellos médicos del Santo Oficio. Poco antes, los citados galenos habían explorado exhaustivamente a Eleno en las cárceles de la Inquisición por orden del Santo Tribunal y tenían sus conclusiones acerca del presunto hermafroditismo de la acusada. Retrospectivamente era la séptima exploración que se llevaba a cabo en el cuerpo de Eleno desde que ésta iniciase los trámites de su segundo matrimonio. Se podría afirmar, sin que pueda ser tachado de exagerado, que las "partes vergonzosas" de Eleno eran los genitales más examinados y palpados en la historia de la medicina española. Sin embargo, como ahora veremos, comparativamente a los anteriores, esta vez el informe de los contra-expertos del Santo Oficio era mucho más técnico y científico.

Previamente a la lectura de su dictamen a los testigos se les tomó juramento. El informe, muy detallado e importante para el desarrollo del proceso, fue el siguiente:

"..tras tomarlos juramento en forma de derecho... les fueron leydas las confesiones hechas por Elena de Céspedes en este Santo Oficio, después que está presa en él, acerca de decir que a tenido seso de hombre siendo mujer y tiniéndole de tal... y aryéndolas leydo e informado acerca desta les mandaron viesen y mirasen a la dicha Elena de Céspedes sus partes vergonzosas y que declaren si es verdad que a tenido y sucede aver tenido seso de hombre como dice los tubo. Con lo que los dichos médicos y cirujano entraron al patio de las cárceles donde fue traída la dicha Elena de Céspedes a la qual vieron y miraron según les fue mandado y volvieron a la audiencia ante los dichos Señores Inquisidores y dijeron como ellos avían visto a la dicha Elena sus partes vergonzosas, la qual es mujer y que nunca fue

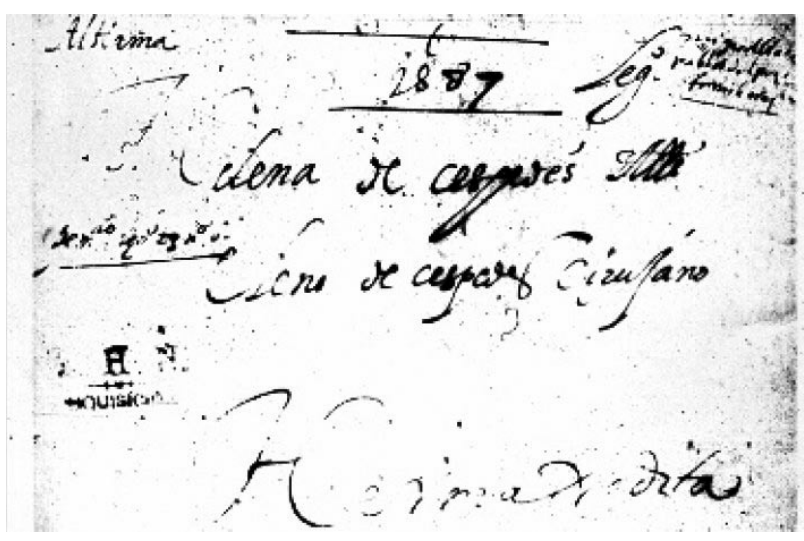

fiGURA 6. Elena de Céspedes "alias Eleno de" cirujano. hermafrodita ni tiene señales de ello, porque ser mujer debe ser claro y demás deso dice que parió y aunque hizo medicina para cegar y apretar que no pareciese natura de mujer, vino al cabo a aparecer y romper sangre del mestruo que era detenido de antes, que es el flujo de sangre que confiesa a ella le vino y que en quanto a lo de los testículos dicen que no ay señal de averlos avido exteriormente, porque si los uviera avido quedara cicatriz aviéndoseles cortado o cauterizado, o el pellejo donde aparecieran averle salido y que ninguna cosa desto ay en la dicha Elena de Céspedes, y que si en algún tiempo los hubiera tenido se viera por las señales que tiene, y que aunque es verdad que los hermafroditas tienen testículos, son ynteriores, de manera que no se pueden ver ni sentir por de fuera, y en quanto a esto dicen que es embuste decir que los tubo fuera. Y en lo que dice la dicha Elena de aber tenido berga de hombre con que dice tratava con otras mujeres, dijeron que aunque es verdad que pudo crecerle lo que llaman nimphe o pudendum que les nace a algunas mujeres en la matriz, pero que esta no lo tiene ni señal de averla tenido y aunque la tuviera no pudiera salir fuera ni tener fuerza para hacer lo que la dicha Elena de Céspedes dice acía, por donde parece claramente ser embuste. $Y$ en quanto dice que para hacerle salir el miembro de hombre que dice tubo la rompieron un pellejo, que es falso, porque aunque tuviera dicha nimphe que es a manera de berga de hombre que se afloja e inyesta con la pasión natural que les viene a las mujeres que la tienen, hera imposible salir por donde dice la dicha Elena de Céspedes, y no tiene señal de aver avido herida para hacerla que saliese ni cicatriz dello, por donde también se ve ser embuste y que si oviera de aver cicatriz donde dice benía el dicho miembro de hombre avía de ser sobre el empeyne, que es la posición donde nace el miembro viril a las mujeres hermafroditas, como todos los médicos y cirujanos dicen. Y ansí les parece que en quanto a esto que es embuste, porque ni le nació ni tiene cicatrices como las tuviera si le naciera y hubiera cortado como ella dice. Y que en quanto a la polución que dice tener, que esto pudiera ser una humedad que suele salir de la madre naturalmente como a todas las demás mujeres en el tiempo que tienen aceso y delectación con varón y que ansí, si este caía en el baso de las otras mujeres con quien trataba pudiera engañarlas. $Y$ ansí por esto y por aver visto a la dicha Elena de Céspedes como la han visto este día ante mí el presidente y secretario y mirándola muy particularmente la natura y las demás partes circunvecinas de mujer, dicen que la dicha Elena de Céspedes nació y es mujer y que como tal tiene todas las señales de mujer y que nunca a sido hermafrodito ni en buena medicina puede ser que lo aya sido, ni tenido miembro de hombre y asi les parece que todos los actos que como hombre dice que hizo, fue con algunos artificios como otras burladoras han hecho con baldreses y otras cosas como se han visto y que es embuste y no cosa natural, que el artificio con 
que hizo el dicho embuste y engañó a las mujeres y estas no lo sabían, que ella lo dirá, y que esto es lo que como médicos pueden juzgar debajo del juramento que tienen hecho y lo firmaron de su nombre".

Después de tan exhaustiva y científica exposición de los expertos médicos del Santo Oficio poca defensa podía quedarle a Eleno. Todos los planteamientos sobre su presunto hermafoditismo habían quedado rebatidos por el dictamen. Pero al igual que era evidente la tozudez de la mulata en seguir afirmando que era hermafrodita, también era proverbial la meticulosidad y lo concienzudo de las investigaciones del Santo Oficio. Tras el examen de sus contra-expertos quedaban pendientes de revocar los controvertidos informes del doctor Francisco Díaz y de los médicos y cirujanos de Yepes. Como vimos anteriormente el Dr. Mantilla ya se había retractado ante el tribunal de Ocaña de su primer dictamen. Restaba pues, convocar a los otros médicos para que confirmaran o no su primera declaración.

El 15-VIII-1587 fueron llamados a declarar ante el Inquisidor Lope de Mendoza a petición de la acusada -ya que se les consideraba testigos a favor de la reo- el doctor Francisco Díaz, médico y cirujano de S.M., y el licenciado Juan de las Casas, médico y vecino de Yepes. Tras tomarles juramento se les obligó a reconocer de nuevo a Eleno en compañía y presencia de los médicos y cirujanos del Santo Oficio para confirmar o retractarse de su primer informe:

"...para averiguar de ser Elena de Céspedes hombre y tener miembro de tal según dicen y afirmar sus deposiciones, o para que se convenzan de lo dicho e firmado es lo contrario de la verdad, e defiendan sus dichas deposiciones según Regla de Medicina con que son graduados, mandamos que vean a la dicha Elena de Céspedes con compañía y presencia de los doctores Fuente y Villalobos y Juan Gómez cirujano, ministros de este Santo Oficio"

Tras el examen conjunto con los otros galenos el tribunal sometió a un severo interrogatorio a ambos acerca de su opinión sobre si Eleno era varón, hermafrodita y si tenía o no miembro de varón. Francisco Díaz además fue interrogado acerca de sí había recibido alguna gratificación por su informe o si le habían prometido algún dinero mas:

"preguntado si vio este, por mandado de Neroni, vicario de Madrid, a una mujer que andaba en hábito de hombre y se llamaba Eleno de Céspedes.

- dijo que sí, y que sabe que era cirujano.

Preguntado que para ver si tenía miembro genital y si podría ser casado y si le vio juntamente con el dr. Mantilla
- dijo que sí y que habiéndose alzado sus ropas el dicho Eleno le vio su miembro genital que estuvo descubierto buen rato delante de entrambos, que tenía su proporción y forma de miembro de hombre proporcionado a su cuerpo, ni grande ni pequeño, antes más grande que pequeño.

Preguntado si le toco con las manos

- dijo que no se acuerda.

Preguntado si tenía seso de mujer

- dijo que aparece delante una señal debajo de los testículos que no advirtió tanto aquesto que pudiera decir que tenía seso de mujer.

Preguntado que le dieron o prometieron porque dijera su declaración

- dijo que le dieron cuatro reales, después de la dicha declaración se le dieron seis"

El Dr. Francisco Díaz y el licenciado Casas se retractaron de su primer informe, y al igual que el Dr. Mantilla hiciera en Ocaña, afirmaron que Eleno era mujer y que su primera errónea apreciación pudo deberse a una "ilusión del demonio o algún arte tan sutil que bastó para engañarles" o quizás "por embuste de la malaventurada mujer que con algún artificio los engañó". Las preguntas del fiscal esta vez fueron mucho más especializadas y a los expertos se les interrogó acerca del 'artificio' que, presuntamente, Eleno se colocaba para simular que era varón:

"preguntado si cree que el acusado tiene alguna señal de recuerdo de hombre hermafrodita

- dijo que no. Que cuando le vio en presencia del dr. Mantilla, médico, le tuvo por hombre y le vio el miembro según tiene declarado

"Preguntados sobre el sexo de mujer que dicen no le vieron, aunque el de hombre fuese artificial, porque dijeron que no podían dejar de verle"

"Dijeron que les parece que el artificio que ella hizo para darles a entender que era hombre y no mujer debía de ser de manera que le encajaba y ponía en su natura de mujer de suerte que encubriese y atapase el miembro de mujer quedando de fuera colgado el de hombre con sus testículos, porque en realidad de verdad ella mostraba su miembro y testículos de hombre muy proporcionado y como la vieron en la buena fe que dicen... no escudriñaron ni miraron tan particularmente las cosas como ahora la miraron, ni la vieron entonces como ahora seso de mujer"

"dijeron estos que confiesan que han sido engañados y que la dicha Elena de Céspedes es mujer y que nunca ha sido hombre ni tiene señal de tal y que no pueden entender la causa mas de que entienden que sea alguna ilusión del demonio, sotileza o embuste de la desaventurada mujer que con algún artificio les enga- 
ñó y a su buena fe... y que la dicha Elena de Céspedes debe ser hechicera" (Figura 7)

Quedaba demostrado pues, en opinión de los expertos, que las argucias de Eleno para simular que era varón iban mucho más allá de la auto-mutilación. Con sus conocimientos médico-quirúrgicos no solo había obturado su vagina utilizando métodos cruentos, sino que posiblemente confeccionó y se colocó algún artificio o postizo que imitando unos genitales masculinos disimulase su naturaleza femenina. Lo sofisticado de la metódica empleada por la cirujana era evidente, sin embargo, a estas alturas del proceso, no podemos obviar las posibles presiones que los médicos del Santo Oficio realizaran sobre Francisco Díaz y el licenciado Casas para que cambiasen su primer informe. Sus afirmaciones sobre la "ilusión del demonio", idénticas a las expresadas por el Dr. Mantilla en Ocaña, hacen pensar en la posibilidad de unas respuestas dirigidas o reconducidas por los otros facultativos para facilitar la acusación de hechicería a la encausada.

Tampoco podemos entrar en disquisiciones acerca de la naturaleza del material con el que Eleno confeccionó el postizo. Era cirujana y la gama sería muy amplia; desde trozos de su misma piel, de queloide cicatricial, o de cualquier otra sustancia moldeable con la que remedar un pene masculino y unos testículos.

A pesar de las reiteradas negaciones de Eleno quien llegó a afirmar durante el juicio: "que el nunca había tenido quenta con el demonio, que Dios le librase de él y que siempre había vivido cristianamente", el 5-X-1587 el fiscal Sotocameno la acusaba formalmente de hechicería solicitando además se le diese tormento para confirmarlo:

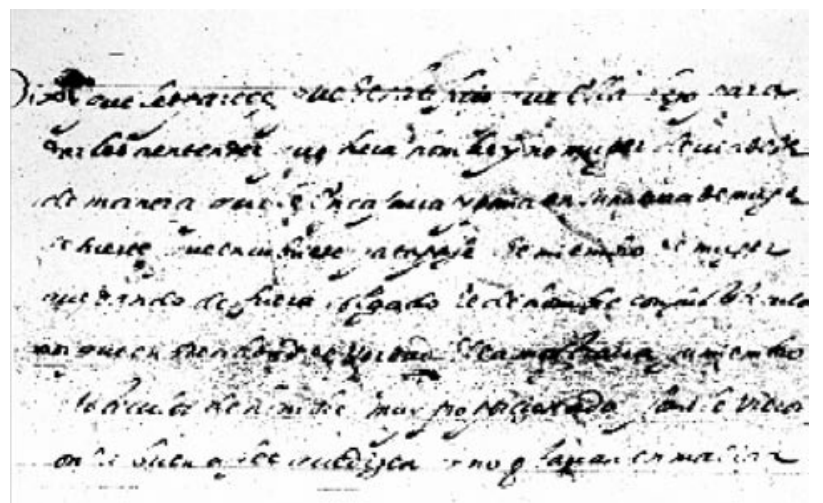

FIGURA 7. Extracto de la declaración del Dr. Francisco Díaz donde afirma que la acusada le había engañado cuando la exploró colocándose un 'artificio' que imitaba unos genitales masculinos y que obturaba su vagina para simular que era varón.
"El licenciado Sotocameno, fiscal del Santo Oficio parezco y digo que en el pleito que trato con Elena de Céspedes, presa en esta inquisición, demás y allende de lo previo y pasado demostrado, la acuso de que ha tenido y tiene pacto tácito o expreso con el diablo, porque siendo como es la susodicha mujer y habiéndolo sido siempre, sin ser posible naturalmente el haber tenido miembro viril, la susodicha con favor y ayuda del demonio hizo demostración de tenerlo para efecto de casarse con otra mujer como ella, en menosprecio del sacramento del matrimonio".

El licenciado Sotocameno

Quedaba pues el juicio visto para sentencia con dos imputaciones principales, la de herejía o apostasía y la de hechicería. La acusada, siendo mujer con menosprecio del sacramento del matrimonio se había casado con otra, engañándola y fingiendo además tener miembro de varón. Según el fiscal, los delitos los había efectuado con favor y ayuda del demonio, por lo que se presumía que la acusada tenía pacto tácito o expreso con Satanás (Figura 8).

\section{El proceso inquisitorial de Toledo un episodio poco conocido en la biografía del Doctor Francisco Díaz y un baldón para su reputación.}

Folch Jou, en un artículo de 1973 (1), sobre el proceso de Elena de Céspedes confirma por vez primera en la bibliografía la participación en el juicio del Doctor Francisco Díaz, "médico y cirujano de Su Majestad", sin comentar ningún hecho relevante que haga pensar que el autor reconociera al cirujano de cámara de Felipe ll y la trascendencia de la opinión especializada del personaje. Por otra parte, Folch opina que Elena de Céspedes o era hermafrodita, o padecía el mal de molas, lo que no concuerda con las características físicas y psicológicas de la acusada; su carácter y su manera de actuar se adecuan más a las de un transexual masculino. La transexualidad había sido descrita solo 20 años antes por Harry Benjamin (11).

Burshatin, en un trabajo más reciente (2), confirma que el tal Francisco Díaz era el eminente cirujano de Felipe II, especializado en afecciones génito-urinarias y autor del "Tratado Nuevamente Impresso" o de Urología de 1588. Para él, las exploraciones corporales de la acusada por el urólogo son muy importantes, ya que en su primera inspección para la determinación del sexo de Eleno (en Madrid) la opción que barajó en su informe no valoraba si Eleno era hombre o mujer, sino hombre o hermafrodita, reafirmándose en que la reo era varón. Sin embargo, en su segunda inspección (en Toledo) el urólogo se retracta y afirma que Eleno es mujer justificando que su anterior error se debió a que la acusada le había engañado con "malas artes". 


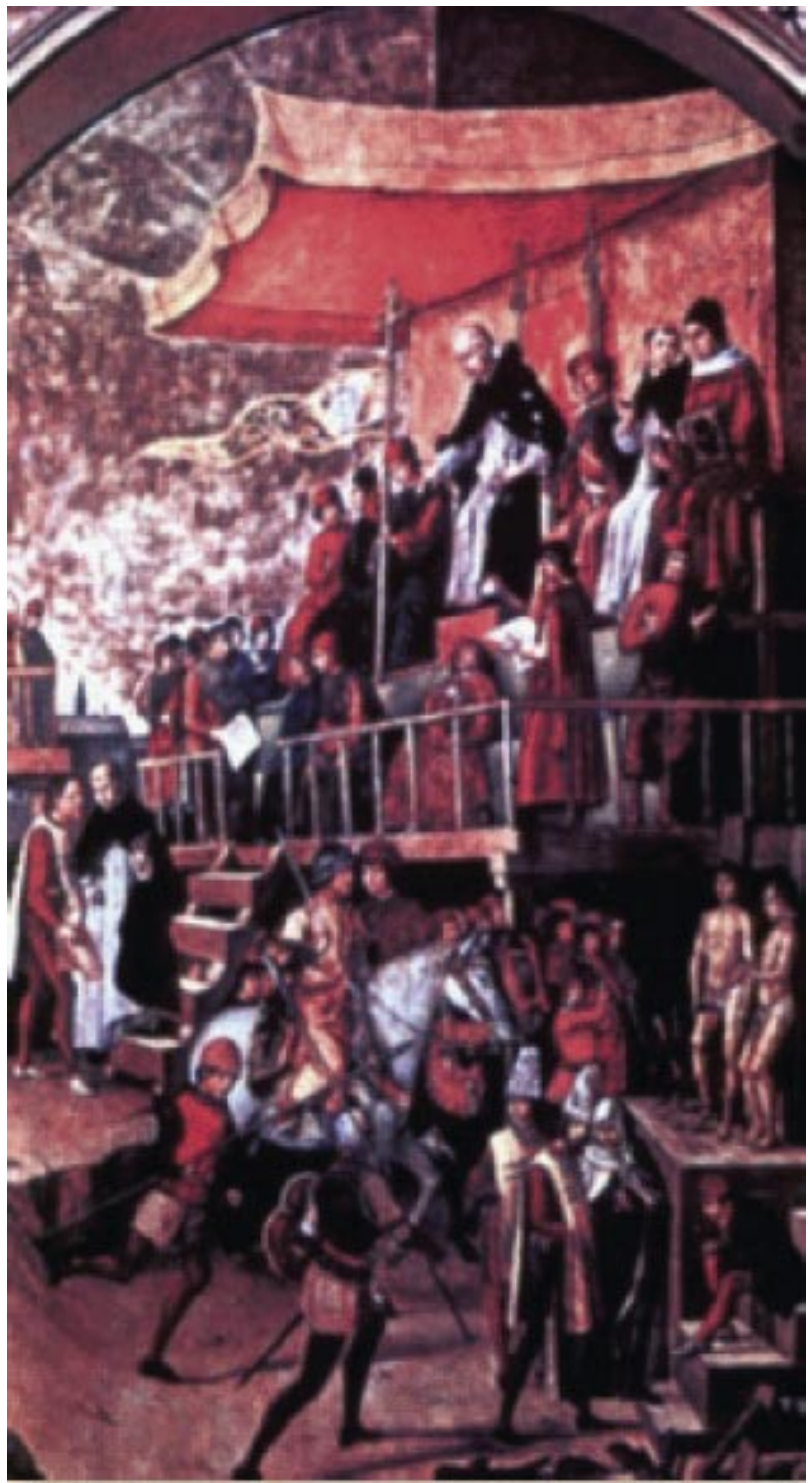

FIGURA 8. Auto de Fe. Pedro Berruguete. Óleo sobre tabla. Museo del Prado.

Burshatin no se explica que un cirujano avezado, experto en afecciones génito-urinarias, pudiera haber sido engañado tan fácilmente por una mujer, al igual que lo fueron los otros médicos y cirujanos. Por ello, pone en duda el segundo informe de Francisco Díaz sopesando que quizás fuera obligado a cambiarlo por temor a ser incriminado de soborno, falsedad, o por presiones del Tribunal de la Inquisición.

Sin embargo en las conclusiones de nuestro libro (10), una vez cotejadas todas las fases de los dos juicios y las exploraciones y actuaciones de los expertos y contraexpertos médicos, como antes se dijo, llegamos a la convicción de que en la primera inspección, Francisco Díaz y Antonio Mantilla no fueron ni mucho menos exhaustivos y que, particular- mente, la exploración del urólogo fue muy superficial obviando o no logrando realizar las pruebas que el caso requería. En su informe de 1586 Francisco Díaz había declarado, sorprendentemente, que el peticionario era hombre y 'que tenía su miembro genital bastante y perfecto con sus testículos, como cualquier hombre y que junto al ano tenía una manera de arrugación que no parecía natura'. En su examen el urólogo no consiguió introducir ningún instrumento por dicha 'arrugación'.

En su comparecencia frente a la Inquisición, Francisco Díaz hubo de retractarse de su primer informe y afirmó que su error 'debió ser por una ilusión del demonio y por las malas artes y embustes de la malaventurada mujer que los engañó'. Acusándola de hechicería, delación muy frecuente para las mujeres transgresoras durante el siglo XVI, trataba de salvar su prestigio, eludir su responsabilidad y evitar ser inculpado a su vez de complicidad o soborno.

Pero, lo que a mi parecer verdaderamente le pondría en evidencia, serían las exploraciones mucho más completas practicadas a la acusada por los contraexpertos del Tribunal Civil y del Santo Oficio (médicos, cirujanos y matronas), quienes "la vieron sus tetas y la metieron una candelilla por su natura", pruebas, sobre todo esta última, que el no había podido realizar a pesar de ser uno de los más notables artífices en la descripción y uso de las candelillas del Renacimiento (12).

Aunque es posible que tras el juicio su nombradía como médico de Cámara quedara algo mermada, y su error quizás supusiera un baldón para su reputación, cuatro siglos después hay que reconocer en su disculpa que en 1587 Francisco Díaz tenía 60 años, (una edad bastante avanzada para la época), que el urólogo estaba mas familiarizado con las afecciones génito-urinarias del varón y que en la segunda exploración la encausada, encarcelada en Ocaña, no había podido automutilarse de nuevo y colocarse el 'postizo' como la primera vez que la reconoció (Figura 9).

Aunque en sus escritos $(12,13)$, Francisco Díaz no hace ninguna referencia al hermafroditismo (sólo hace mención de la nimphea = clitoromegalia en el "Compendio de Cirugía") o a los intersexos, es seguro que conocía bien la androginia. En su biblioteca (4) se encontraron las obras de Plinio el Viejo (Historia Natural), Guy de Chauliac (Chirurgia Magna) y la de Amato Lusitano (Curationem Medicinalium centuriae septem) en las que existen amplias referencias sobre el hermafroditismo y las transformaciones sexuales. Por eso en la primera exploración su principal preocupación fue descartar el hermafrodi- 
tismo de Eleno, extremo que hace destacar en su informe. Otra cosa es que la encausada, que también era cirujana titulada, le engañara mediante métodos fraudulentos lo cual, con nuestros conocimientos actuales, le disculpa en parte. Al fin y al cabo Elena/ o de Céspedes era un transexual masculino, o sea, una mujer que mentalmente tiene la convicción de pertenecer al sexo contrario y se ve atrapada en un cuerpo femenino. Hoy sabemos que estos desgraciados seres sienten una gran aversión por su anatomía y tratan por todos los medios de modificarla para adaptar su cuerpo al género al que realmente creen pertenecer. Gracias a sus conocimientos en cirugía Elena se había automutilado desbaratando sus pechos, obturando quirúrgicamente su vagina y colocándose un 'artificio' para simular que era varón.

Aunque al final no lograra su principal objetivo (que es el mismo que en la actualidad persiguen todos los transexuales masculinos): ser reconocida como varón, y fuera condenada a 200 azotes y reclusión durante diez años en un hospital trabajando gratis en sus enfermerías, su tozudez y las dudas que debió despertar su ambiguedad en el Santo Tribunal le salvaron de la hoguera en una época en la que la mujer no gozaba de ningún privilegio.

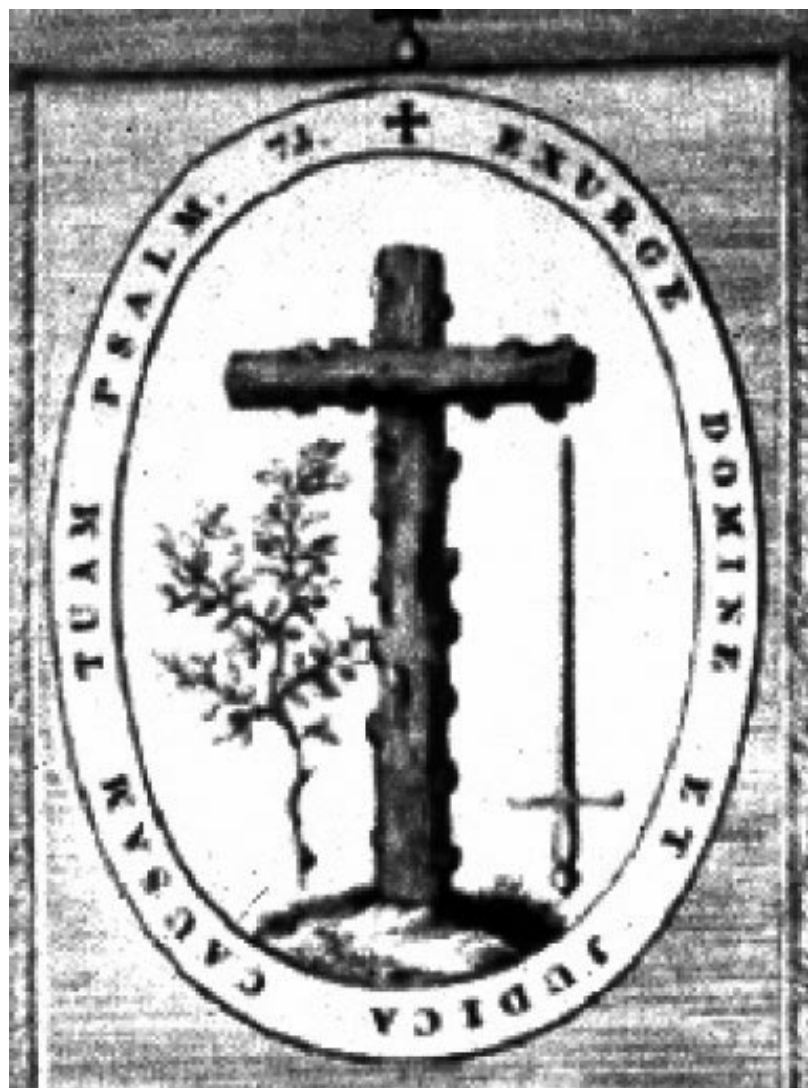

FIGURA 9. Escudo de la Inquisición. Grabado de B. Picart. Biblioteca Nacional de Madrid.
BIBLIOGRAFÍA y LECTURAS RECOMENDADAS ( ${ }^{*}$ lectura de interés $y^{* *}$ lectura fundamental)

*1. FOLCH JOU, G.; MUÑOZ CALVO, M.S.: “Un pretendido caso de hermafroditismo en el siglo XVI". Bol. Soc. Historia de la Farmacia, 93: 20, 1973.

**2. BURSHATIN, I.: "Written on the body. Slave or hermaphrodite in sixteenth-century Spain". Queer Iberia. Sexualities, cultures, and croissings, from the Middle ages to the Renaissance. Ed. by J. Blackmore and G. S. Hutcheson. Duke University Press. Durham, pags. 420-456, London, 1999.

3. SUENDER, E.: "Noticia de las obras del Doctor Francisco Díaz, célebre médico del siglo XVI". Ed. M. Ginestá Hermanos, Madrid, 1888.

4. ESCRIBANO GARCÍA, V.: "La Cirugía y los Cirujanos españoles del siglo XVI. El Dr. Francisco Díaz". Imprenta H. de Paulino V. Traveset, Granada, 1938.

5. GRANJEL, L.S.: "Retablo Histórico de la Urología Española. El Urólogo Francisco Díaz”. Capítulo V, pag. 57. Ed. Instituto de la Historia de la Medicina Española y Real Academia de Medicina de Salamanca, Salamanca, 1986.

6. RIERA, J.: "La obra urológica de Francisco Díaz. En: Cirujanos, Urólogos y Algebristas del Renacimiento y Barroco". Acta Histórico-Médica Vallisoletana. XXIX, Pags. 39-87, Valladolid, 1990.

7. MAGANTO PAVÓN, E.: "El Doctor Francisco Díaz y su época. Biografía conmemorativa en el cuarto centenario de su fallecimiento". Eduard Fabregat Editor, Barcelona, 1990.

8. MAGANTO PAVÓN, E.; GARCÍA NAVAS, R.; GARCÍA ORTELLS, D. y cols.: "La intervención del Dr. Francisco Díaz en el proceso inquisitorial contra Elena/o de Céspedes, una cirujana transexual condenada por la inquisición de Toledo en 1587". Comunicación Poster 42 para el LXIX Congreso Nal.Urología, Oviedo, 2004.

**9. ARCHIVO HISTÓRICO NACIONAL DE MADRID: Sección Inquisición, Legajo 234, expediente 24.

**10. MAGANTO PAVÓN, E.: “El Proceso Inquisitorial contra Elena/o de Céspedes (1587-1588) (Biografía de una cirujana transexual del siglo XVI)". Método Gráfico. Madrid. 2007.

*11. BENJAMIN, H.: "Transvestism and Transsexualism”. Am. Psichiatry, 8: 219, 1954.

12. DÍAZ, F.: “Tratado Nuevamente Impresso de Todas las Enfermedades de los Riñones, Vexiga y Carnosidades de la Verga y Urina”. Ed. Francisco Sánchez, Madrid, 1588.

13. DÍAZ, F.: "Compendio de Chirurgia". Ed. Pedro Cosín, Madrid, 1575. 